\title{
Attitudes of parents and children towards people with disabilities and their integration into society
}

\section{KEYWORDS}

disability, attitudes, attitudes towards disability, types of disability, interdisciplinary transfer, symbolic interaction, labelling, ecological model, integration

\begin{abstract}
Hila Fuchs, Attitudes of parents and children towards people with disabilities and their integration into society. Culture - Society - Education no. 2(20) 2021, Poznań 2021, pp. 91-109, Adam Mickiewicz University Press. ISSN 2300-0422, ISSN (Online) 2719-2717. DOI 10.14746/ kse.2021.20.5
\end{abstract}

This study is part of a broader study that examined the correlation between cognitive, psychological, and behavioural abilities in parents and their children. It focuses on the correlations between attitude to disability and the integration of people with disabilities among parents and their children.

This study is a two-part integrated study. In the first part, the data were collected and analysed according to a quantitative methodology to examine access to disabilities, the integration of people with disabilities, and the factors that influence attitudes, feelings, and willingness to integrate with the general population. In the second part, the data were collected and analysed according to a qualitative methodology in order to examine the relationship of attitudes of parents and their children towards people with disabilities and the integration of people with disabilities.

* ORCID: https://orcid.org/0000-0001-7510-3344.

** The text is the result of research carried out for a doctoral thesis entitled „Psychological Flexibility and Attitudes towards Disability. Psycho-Socio-Educational Study of the Relations between Parents and Children". The PhD was defended in 2021 at the Faculty of Educational Studies. The supervisor of the doctoral thesis was professor Slawomir Banaszak. 
The study population included 150 subjects in the general questionnaire and 60 subjects in the open-ended questionnaire. 30 pairs of parents and their children. The study found a positive relationship between parents' attitudes towards disabilities and their children's attitudes. Some of the attitudes can be explained by internal psychologists' processes, some by socio-cultural perceptions, and parental transfer through education and modelling.

\section{Theoretical Framework}

Since the beginning of the $20^{\text {th }}$ century, the study of attitudes has focused on the connection between attitude elements. The philosophical question dealt with the issue of personal identity and the individual's responsibility for his actions. From the psychological point of view, the question about connection dealt with the question of the make-up of the soul and the compatibility between the different parts of the ego. From a practical point of view, the connection dealt with predicting and influencing behaviour (Geva, 2014).

Attitudes are acquired in a learning process. According to the behavioural approach, attitudes crystallize under the influence of a mechanism of operant conditioning in trial and error processes. According to this mechanism, behaviour is stimulus-response based, is determined by its results, and shaped by reinforcement. Thus, when an attitude is strengthened, and its results prove beneficial to the individual, it will be preserved and established. According to the cognitive learning theory, the connection between stimulus and response can be explained only through mental processes.

Cognitive learning is based on information processing among multi-sensory models. According to this theory, attitudes are acquired basing on knowledge, in a process that involves interpreting many properties of an object and the formulation of evaluations based on rational considerations ( $i b i d$.). According to theories of mediated learning, man is a social creature by nature and acquires preconceived and established attitudes from society and the culture around him. A "database" of preferences, opinions, evaluations, patterns, experiences, and more accumulated over generations is acquired by the individual from others in social processes that include observing (ibid.).

Dictionary definitions of the term disability focus on factors that prevent individuals from achieving desired or "normal" outcomes, including inferiority, lack, 
incompetence, avoidance, and disqualification. Legal definitions include legal incompetence. Medical definitions (Steadman, 1976) distinguish between disability as a legal, medical condition that indicates loss of functioning and earning capacity and disablement that refers to loss of function without loss of work capacity. These definitions refer to disability as a medical term with medical significance and importance (Linton, 1998). In the second half of the 1970s, the term disabled was replaced with people with disabilities in order to substantiate the statement that disability is one of the characteristics of the individual and not its essence. Since the 1990s, the term disabled has become a secondary characteristic of individual and group characteristics, intending to emphasize and treat it with due attention and promote the rights of people with disabilities (ibid.).

Calls for minimizing classifications and labels and conceptual changes (Oliver, 1995) influenced and shaped the social discourse concerning people with disabilities. Contemporary discourse deals with the complexity of the definitions and opposes the traditional perceptions that perceived the type of medical disability and its implications on functioning due to the difficulties disabled individuals have integrating into society (Gilad \& Barak, 2012). The definitions that began to be established in the 2000s were characterized by humanistic concepts that exemplify the ecological model (Reiter, Kupferberg \& Gilat, 2017). The definitions under this approach diverge from setting clear boundaries and refuse to address categorical characteristics that distinguish a particular population from another population. In contrast, they deal with disability and dependence as a universal and inherent common denominator of human existence (Ziv, Moore \& Eichengreen, 2016).

The past four decades have brought modifications and changes in the perception of people with disabilities. The new concepts, which work to transform the reality of people with disabilities from exclusion to social inclusion and equality, are based on deep processes of change in terms, values, and social structures (Gilad \& Barak, 2012).

Negative attitudes towards disabilities are already discernible in the early stages of development (Krahé \& Altwasser, 2006). Studies on young children's perceptions have found that they can categorize individuals as impaired and unclassifiable, with a clear preference for people who do not have an atypical characteristic (Richardson, Goodman, Hastorf \& Dornbusch, 1961). Children's awareness of individual differences develops very early. By the end of the first year of life, children develop awareness about their separateness from others (Stern, 1995). By the age of three, they can describe themselves in basic categorical terms and characteristics that identify them (Stipek, Gralinski \& Kopp, 1990). They can compare themselves to external standards of appearance and behaviour. Before entering school, they 
formulate a well-developed perception of the self and can reflect how they appear to others and what differentiates them from others (Gilmore \& Howard, 2016). During elementary school years, self-perception becomes increasingly influenced by environmental responses (DiBiase \& Miller, 2012) and comparisons to others (Gilmore \& Howard, 2016). Their awareness of characteristics that affiliate them with others and those that make them stand out as different broadens and is no longer limited to responses made by members of their inner circle (ibid.). As their age increases, children's internal and interpersonal insights continue to develop and become more complex and sophisticated, making comparison and evaluation skills. During adolescence, reflective and perspective abilities are higher and allow, but do not guarantee, a more comprehensive understanding and acceptance of oneself and others (Gilmore \& Howard, 2016). Toddlerhood and early childhood play a significant role in shaping the child's belief system and value system. The influence of parental behaviour and messages, the influence of early experiences and their connection to emotions and behaviours, messages, values, and perceptions transmitted, directly and indirectly, have a significant influence on the child's attitudes and perceptions regarding disabilities in society (Livneh, 1983).

Lee \& Rodda (1994: 231) claim that children acquire beliefs and perceptions about disabilities through learning and social construction. Studies have shown that a relationship with peers with disabilities throughout a child's maturation, accompanied by mediation, can contribute to forming a positive, humane and accepting attitude towards disability (Krahé \& Altwasser, 2006). Conversely, exposure without intermediary means poses a risk for adverse consequences such as rejection, defamation, labelling, and conflict (Brown, Odom \& McConnell, 2008). Intermediary measures include significant interactions with individuals with disabilities, adult role models, and comprehensive and accurate information about disability (Gilmore \& Howard, 2016). Conditioned perceptions and responses acquired through social learning and social and cultural norms reinforce beauty, youth, and a healthy body (Livneh, 1982). These ideas contribute to the perceptions that a disability is a threat to the body image (Schilder, 1935), a state of discomfort that can be caused by an encounter with an unexpected body and a mismatch between it and the expected body perception (Livneh 1982), to anxieties that arise in the individual in cases of bodily impairment (Fine, 1978; Whiteman \& Lukoff, 1965), to avoidance due to fear of potential harm (Roessler \& Bolton, 1978), to separation anxiety (Siller, Chapman, Ferguson \& Vann, 1967), to fear of infection or transmission (Sigerist, 1964) and to associating disabilities with death (Endres, 1979; Leviton, 1975; Livneh, 1980; Siller, 1964). These perceptions lead to rejection and avoidance of interaction with people with disabilities. 
Psychodynamic processes from the early stages of development describe unconscious psychological forces that shape the approach to disability in society and the differentiation children make between the disabled and those who are not disabled (Livneh, 1982, 2012). Some processes appear in early childhood and can be considered merely related to childhood experiences, but they are still perceived to be meaningful in shaping the child's approach to disabilities. Psychodynamic approaches view the individual's development and personality due to the mutual influence between hereditary and biological factors and the individual's relationships in his early years with the significant people in his environment (Becker, 2009). According to Freud (Yarom, 2007), the stages of psychodynamic development develop through conflicts between different structures that comprise the mind and require creating a balance between impulses and instincts, social and moral constraints, and the need to intervene and mediate between them. In order to enable adaptation, the individual constructs defence mechanisms that help him cope with the anxiety that arises from the conflict and then adapt to social demands (Becker, 2009). Parents symbolize society and social expectations for the child. A child's desire for love and support from his parents motivates him to identify and internalize with the social and cultural values they represent (Greenberg \& Mitchell, 1983).

In the theory of symbolic interaction, society is perceived as the product of the interaction processes of individuals (Reynolds \& Herman-Kinney, 2003). Thus, social reality is dynamic and can be built by individuals in society (Tal, 2013). In this theoretical framework, Goffman (1963) and Berger \& Luckmann (1966) argued that a stigma toward a person or a group takes on significance in the processes of interactions and social construction (ibid.).

Chubon (1992) refers to behavioural theories, consistent theories, the information integration theory, and the role theory as four main categories that influence the formation, design, and change of general attitudes, stigmas, and attitudes towards disability. According to Horne (1985), attitudes are built basing on behavioural learning to respond to environmental stimuli and through reinforcement (Daruwalla \& Darcy, 2005). An attitude towards a disability reinforced by the behavioural aspect will tend to preserve and establish itself as the tendency to avoid (Corrigan, Markowitz, Watson, Rowan \& Kubiak, 2003; Jones \& Corrigan, 2014). Gergen (1986) and Gergen \& Gergen (1986) argue that initiating interaction and practicing communication methods are significant determinants of behavioural influence on attitudes towards disabilities (Daruwalla \& Darcy, 2005).

Many theories describe psychological and social development as a transformative process consisting of primary stages (Cohen, Onunaku, Clothier \& Poppe, 2005; Kail, 2014; Berger, 2009; Berk, 2013). 
Bronfenberg's model (1986), which evolved into the Bio-ecological theory of Damon \& Lerner (2006), is based on a contextual perspective and argues that an individual develops within a complex and multi-dimensional context. The family system, parental practices, parent-child relationship, peer group, and school influence an individual's development (Ben-David \& Nel, 2013; Bonfenbrenner, 1994). In the past, parents played a crucial role in raising a healthy child by providing basic needs, including love and security (Erath \& Bierman, 2006; Lerner, Brennan, Noh \& Wilson, 2015; Pleck, 2007; Scrimgeour, Blandon, Stifter \& Buss, 2013). Today parental influence is seen as a central component in the influence of the family system as a whole on a child's development (Bronfenbrenner, 1994; Ely, Gleason, MacGibbon \& Zaretsky, 2001; Patterson, DeBaryshe \& Ramsey, 1989; Berger, 2009), which is influenced by factors in parental practices, the parent-child relationship, parental stress, parental behaviour, and parenting styles (Esdaile \& Greenwood, 2003; Algood, Harris \& Hong, 2013).

Parenting style is defined as a behavioural transfer of the parent's attitudes toward their child, expressed in his education style, that affects the family emotional climate (Darling \& Steinberg, 1993). Baumrind's model outlines three parenting styles (Baumrind, 1977; Robinson, Mandleco, Olsen \& Hart, 1995; Robinson, 1996).

Intergenerational Transfer is part of the socialization process and is defined as the Transfer of resources, such as attitudes and behaviours, between different age groups over time and with inherited influence (Lee, 2014). The theory based on intergenerational Transfer is based on a central assumption that an individual's family plays a central role in forming his personality (Bowen, 1978; Rabstejnek, 2012). The Family Systems Theory (Bowen, 1966) argues that all parts of the family are interrelated and affect one another, and therefore intergenerational transmission occurs among all family members (Britt, 2016). The Social Learning Theory views the learning process as a cognitive process in a social context. Parents significantly influence their children's behaviour because they serve as role models (Bandura \& Simon, 1977).

Fonagy \& Target (2002) view the parent as responsible for instilling in the child reflective and mental abilities essential to his emotional and social development and imparting empathy and self-regulation skills. These abilities develop, in his opinion, alongside exposure of his emotions and contain his feelings while preserving the sense of separateness (ibid.).

Studies have shown that empathic, warm, and present parents reinforce pro-social behaviour in their children (Musick \& Wilson, 2008; Bekkers, 2007). Studies examining the origins of caring for others have found that they are shaped by learning processes through family life experiences (Adriani \& Sonderegger, 2009; Bekkers, 2007). Various studies have shown that altruistic behaviours, mutual trust, and co- 
operation in inter-family interaction are components that promote intergenerational transmission of democratic values and prosocial values (Penner, Dovidio, Piliavin \& Schroeder, 2005; Dotti Sani \& Treas, 2016). The Social Learning Theory (Bandura $\&$ Simon, 1977) holds that intergenerational Transfer occurs through various types of stimulus modelling (Herrmann, Hernández-Lloreda, Hare \& Tomasello, 2007). These models include a model based on an open display of desirable values, attitudes, and behaviours (Matthews, Hempel \& Howell, 2010; Steinberg \& Wilhelm, 2003), a model based on detailed descriptions of values and desirable behaviour in a family discourse (Zukin, Keeter, Andolina, Jenkins \& Delli-Carpini, 2006; Andolina, Jenkins, Zukin \& Keeter, 2003), a model based on family symbolism that fosters the institution of value-based activity (Bekkers, 2007) and a model based on the indirect influence of the family culture based on giving, helping, and social activity, which influences the family atmosphere (Nesbit, 2013).

The study was conducted in two stages - In the first phase, 150 questionnaires on attitudes towards disabilities (Halperin, Elad-Stranger \& Andvolt, 2016) were administered to examine attitudes towards disabilities and integration in general society. The second phase includes 60 open-ended questionnaires that deal with integrating individuals with disabilities in the residential environment and the educational environment. Adults were asked to fill in their questionnaires first and then pass the questionnaire to the child. If the child needed mediation, the parent was asked to mediate it. The last question dealt with the shared experience of filling in the questionnaires. The parents and children were asked to answer it together.

\section{Results}

The study was an integrated study and therefore integrated different types of data. Analysis of the quantitative data included examining the correlation, positively and negatively, between the psychological flexibility and attitudes towards people with disabilities questionnaires. The analysis of the qualitative data included analysis of open questionnaires, which examined the correlations.

\section{Quantitative results}

Table 1 describes the descriptive statistics for the core variables. As Table 2 shows, the dependent variable, a willingness to integrate individuals with disabilities, had an average score of 5.08 out of $6.00(S D=0.57)$. Moral behaviour had an aver- 
age score of 4.41 out of $6.55(S D=1.20)$. Social perception of individuals with disabilities had an average score of 4.63 out of $6.00(S D=0.66)$. Familiarity with individuals with disabilities had an average score of 3.16 out of $7.00(S D=1.95)$. Finally, self-perception as individuals with disabilities had an average score of 0.09 out of $2.00(S D=0.35)$. With this variable, only 6 participants had an average score higher than 0 and were considered as outliers. Therefore, this variable was not included in the rest of the analysis.

Table 1. Means, standard deviations, and ranges of the core variables

\begin{tabular}{|l|c|c|}
\hline & Mean & Standard deviation \\
\hline Willing to integrate individuals with disabilities & 5.08 & 0.60 \\
\hline Moral behavior & 4.14 & 1.20 \\
\hline Social perception of individuals with disabilities & 4.63 & 0.66 \\
\hline Feeling towards individuals with disabilities & 4.52 & 0.57 \\
\hline Familiarity with individuals with disabilities & 3.16 & 1.95 \\
\hline Self-perception as individuals with disabilities & 0.09 & 0.35 \\
\hline
\end{tabular}

In order to assess the correlations between the core variables, Pearson correlations were conducted between all the variables. Results show a positive correlation between the participants' moral behaviour and feelings towards individuals with disabilities $(r=0.21, p<0.01)$. In addition, there were positive correlations between the social perception of individuals with disabilities and their feelings towards individuals with disabilities $(r=0.24, p<0.01)$. Finally, there was a positive correlation between the participants' familiarity with individuals with disabilities and their willingness to integrate individuals with disabilities $(r=0.27, p<0.01)$. That means that the more the participants had positive feelings towards individuals with disabilities, the more they exhibited moral behaviour, and the higher their acceptance levels were. In addition, the greater the participants' familiarity with individuals with disabilities was, the more positive feelings they had towards individuals with disabilities.

Table 2. Correlations between the core variables

\begin{tabular}{|l|c|c|c|c|c|}
\hline & $\mathbf{1}$ & $\mathbf{2}$ & $\mathbf{3}$ & $\mathbf{4}$ & $\mathbf{5}$ \\
\hline Moral behavior & & & & & \\
\hline Social perception of individuals with disabilities & 0.13 & $0.16^{\star}$ & & & \\
\hline Willing to integrate individuals with disabilities & $0.21^{\star *}$ & 0.12 & -0.01 & & \\
\hline Feeling towards individuals with disabilities & 0.10 & $0.24^{\star *}$ & 0.08 & 0.02 & \\
\hline Familiarity with individuals with disabilities & 0.06 & 0.14 & -0.02 & $0.27^{\star *}$ & 0.08 \\
\hline
\end{tabular}

${ }^{*} p<0.05,{ }^{* *} p<0.01$. 


\section{Predicting willingness to integrate individuals with disabilities}

A multiple linear regression analysis was performed, with independent variables as the core variables: moral behaviour, social perception of individuals with disabilities, feeling towards individuals with disabilities, familiarity with individuals with disabilities, and the demographic variables age and marital status that were found to have a significant direct association with willingness to integrate individuals with disabilities. The regression model showed that the independent variables accounted for approximately $23.50 \%$ of the total variance in the willingness to integrate individuals with disabilities $(F(7,134)=5.89, p<0.001)$. Results showed strong positive correlations between moral behaviour $(\beta=0.21, p<0.01)$, familiarity with individuals with disabilities $(\beta=0.27, p<0.01)$, being not married $(\beta=0.19, p=0.01)$ and willing to integrate individuals with disabilities. In addition, there was a negative correlation between age and willingness to integrate individuals with disabilities $(\beta=-0.28, p<0.01)$. Willingness to integrate individuals with disabilities predicts more moral behaviour, higher familiarity with individuals with disabilities, being single, and being younger.

Table 3. Standardized and unstandardized coefficients to predict willingness to integrate individuals with disabilities based on the core and demographic variables

\begin{tabular}{|l|r|r|r|r|r|}
\hline & $B$ & $\begin{array}{c}\text { Std } \\
\text { Error }\end{array}$ & $B$ & $T$ & $p$ \\
\hline Moral behavior & 0.11 & 0.04 & 0.21 & 2.69 & $<0.01$ \\
\hline Social perception of individuals with disabilities & 0.05 & 0.07 & 0.05 & 0.63 & 0.53 \\
\hline Feeling towards individuals with disabilities & 0.05 & 0.08 & 0.05 & 0.61 & 0.54 \\
\hline Familiarity with individuals with disabilities & 0.09 & 0.02 & 0.27 & 3.46 & $<0.01$ \\
\hline Age & -0.01 & 0.00 & -0.28 & -3.52 & $<0.01$ \\
\hline Marital status (not married) & 0.27 & 0.11 & 0.19 & 2.52 & 0.01 \\
\hline
\end{tabular}

In the final linear regression, it was additionally found that moral behaviour and familiarity with individuals with disabilities also predict the willingness to integrate individuals with disabilities into society.

\section{Qualitative results}

Perceptions related to the type of disability: One of the most essential themes expressed in the results is that there are differences in various types of disabilities 
regarding the ability of both parents and children to accept and integrate these individuals. That is, some disabilities are far more challenging to accept in comparison to others. It seems that both parents and children are more ease in accepting individuals who are not perceived as a threat to their personal safety. That means that individuals who suffer due to genetic disorder (e.g., Autism) or a significant accident (e.g., burn) are easier to accept. On the other hand, individuals who have a background in violence and crime have a much worse chance of being accepted.

Parents mainly emphasized the need for keeping society and their children specifically safe in the presence of individuals with disabilities, meaning, they chose these types of disabilities which will not harm their children physically or psychologically. In addition, another criterion to integrate individuals with disabilities is the ability to feel empathy towards the person. On the other hand, parents found it very difficult to accept individuals with disabilities, potentially harming their children. Parents specifically expressed negative attitudes in integrating individuals with infectious diseases or a history of violence. These two types of disabilities are perceived as specifically dangerous, and therefore, parents have significant resistance to individuals with those disabilities.

Motivation for integration: An exciting consideration of parents concerning integrated individuals with disabilities is their desire to create a more diverse society with people who can help and learn from each other. Hence, parents place high importance on integrating individuals with disabilities to create a society where people can learn from one another's experiences and help each other.

One of the most important motives of children in integrating individuals with disabilities is to help them from a humanistic point of view. As seen, children are very mature and positive in their attitudes regarding helping and integrating individuals with disabilities. They state that despite the initial fear and stigma, they are willing to interact with individuals with disabilities and help them. They have a flexible attitude in accepting other people with significant difficulties in their appearance or behaviour. It is important to note that children feel more positive if they feel safe. When children feel that individuals with disabilities might harm them, they choose not to engage.

The participant's responses: Results showed interesting patterns regarding how parents responded to the questionnaires. Specifically, in the beginning, when parents filled in their questionnaires, they were a little uncomfortable and even anxious in some cases. It seems that the issue of individuals with disabilities is not easy for them to deal with. However, when responding to the open text questionnaires with their children, parents felt they need to show a more open-minded approach and reported a positive and even self-enhancement experience. 
The participant's responses, from both parents and their children, analysed regarding critical perceptions and themes that arose regarding the willingness to integrate; critical perceptions and themes that arose regarding the unwillingness to integrate; attitudes, approaches, general perceptions about integration, and observations from the shared experience of completing the questionnaire.

Correlation: Among a high proportion of the participants, there is a correlation between attitudes, topics, and content brought up by parents and their children. The issue of danger and an uncomfortable feeling repeatedly appeared as a common central theme among parents and children, influencing an unwillingness to integrate. More diverse answers were provided by both parents and children concerning the willingness to integrate, and shared perceptions were once again discerned among parents and their children. Recurring themes related to the importance of integration, willingness to integrate out of familiarity with various disabilities, a desire to help, a desire to interact, the perception that integration is mutually beneficial, and a willingness to integrate individuals who are perceived as "harmless". There was a match between the parent's attitudes and the child's attitudes toward integration for most participants.

\section{Discussion and conclusions}

The present study examines the relationship between parents' attitudes toward disability and integration and their children's attitudes toward disability and integration.

According to Bandura \& Simon (1977), parents significantly influence their children's behaviour because they serve as role models. The qualitative results demonstrate this effect by pointing to the existence of common morality in parents and their children both in terms of willingness to integrate and resistance to integration and standard general perceptions towards integration of people with disabilities. Among the child's parents in this study, cognitive biases (Hammond, Keeney \& Raiffa, 2006) towards specific disabilities were prominent. These biases were expressed in the central position about an unwillingness to integrate, characterized by fear of danger, harm, and unpleasant feelings in encountering the individual with disabilities. These unpleasant feelings are based on the individual being perceived as violent, dangerous, or incapable of change. This position appeared respectively in pairs of children and parents. Other common perceptions have arisen related to a lack of belief in the individual's ability to integrate, a parent's or child's sense of helplessness, and difficulty coping. These perceptions also increased respectively in pairs of children and parents. 
Positions common to both parents and their children regarding a willingness to integrate referred to a willingness to integrate a specific disability based on acquaintance, contribution or personal interest, ability to identify with the disability, and assist. Other standard positions that have emerged are willingness to accept change and go through a process, a desire for interaction, a vision of mutual contribution, and humanitarian, rational, and social perceptions. This result is supported by studies that have shown that parent empathy and presence reinforce prosocial behaviour among their children (Musick \& Wilson, 2008; Bekkers, 2007)

A significant similarity was also presented between the feelings, thoughts, and perceptions of the parents and the feelings, thoughts, and perceptions of their children regarding people with disabilities and the integration of people with disabilities. In cases where no common denominator was found, the children's perceptions of integration tended to be more positive, and a humanitarian point of view was prominent. Dahl, Schuck \& Campos (2013) showed in their studies that a consistent parental response that includes an explanation helps the child draw conclusions about his or her behaviour and guide future behaviours in a way that is consistent with preserving the rights and well-being of others. In this study, the questionnaires were filled in by parents and children jointly. The parents were asked to mediate to the child unfamiliar or challenging situations that arose from the questionnaire and at the same time allow him to offer his personal opinions. The mediation and the leeway the child received in filling in the questionnaire helped the children to face challenging questions and detailed descriptions and, at the same time, come forth with positive attitudes towards integration.

O'Brien, Larson \& Murrell (2008) and Coatsworth, Duncan, Greenberg \& Nix (2010) argued that the family context is significant for children's development and functioning. The child's exposure to experiences and challenges develops his or her ability to respond flexibly and openly to everyday experiences. The responses of the parents and their children showed that the more the children are exposed to discourse, even while filling in the questionnaire itself, and the more exposed they are to a variety of everyday events and people, the more positive they are towards integration and the readier they are for mutual acquaintance and learning. Filling in the questionnaires presented an interesting pattern among the parent population. Parents initially reported a feeling of discomfort and difficulty coping in their encounter with the questions. However, when asked to mediate the questionnaire to their children, they committed to showing more openness. Following the process, they reported insights about themselves. Parents reported, among other things, thinking about education and about which perceptions parents convey in their education while understanding that there are often similarities 
in perceptions. They expressed their difficulty in discovering unacceptable sides in themselves, difficulty admitting their struggle in being accepting, understanding that there is a projection of personal apprehension on the child and the concern over whether or not to expose him to certain things, understanding that the parent's openness affects the child's openness, dealing with things they prefer not to deal with daily, and an opportunity to examine themselves personally. At the same time, the parents' admiration for the level of openness, acceptance, and maturity of their children rose.

An analysis of the open-ended questionnaires revealed that the adult population tended to choose disabilities that were familiar to them and felt they had the tools to cope. Some noted the anxiety caused by differences and thought that the exposure would help with acquaintance and affinity as described in the theories presented. This finding is consistent with Horne's (1985) theory that attitudes are constructed based on behavioural learning in response to environmental stimuli and through reinforcements (Daruwalla \& Darcy, 2005) As well as with the findings of Triandis (1971) and Gergen (1986) that creating interactions and practising communication practices are significant factors in behavioural influence on attitudes toward disabilities (Daruwalla \& Darcy, 2005).

The population of children mainly noted fear and differences between thought and emotion. This result is consistent with other studies conducted in the field and showed that the relationship of children with disabled peers, which is based on meaningful interactions and broad interaction, contributes to the formation of a positive, humane, and accepting attitude (Gilmore \& Howard, 2016; Krahé \& Altwasser, 2006).

The preference for individuals with disabilities when the subject perceives himself as able to assist them appeared in both the parent's questionnaires and the child's questionnaires. This finding can have several explanations: Yamamoto and SafiliosRothschild (1970) found that when an ethology of deviation is linked to responsibility, there is an impact of the disability on the moral dimensions of the individual with the disability alongside the social responsibility for "correcting it" (Yamamoto, 1970; Safilios-Rothschild, 1970). Siller and colleague (1967) found that in the presence of a person with a disability, a guilty feeling arises in the individual about his health and bodily integrity and the need to avoid or act on the issue. Also, Festinger's cognitive dissonance theory (1957) assumes that the human cognitive system is characterized by a natural desire for balance and matching between its elements. Disrupting the balance between the elements causes psychological discomfort, and therefore the individual will want to reduce the dissonance by avoidance or action (Geva, 2014; Daruwalla \& Darcy, 2005). This type of preference is consistent with the anxiety that 
arises in uncertain situations and with the desire for control and self-determination in these situations. According to this view, the need to assist is based, among other things, on the need to create a sense of certainty in unfamiliar situations and stereotypical perceptions that perceive the disabled person as a person who needs assistance and not as an equal person with whom mutual and authentic communication can be produced. The study shows that coping with unfamiliar situations significantly affects positive and negative perceptions and behaviours. The children noted fear of the unfamiliar. The process of exposure they went through via the questionnaire led to a desire for knowledge and familiarity despite their apprehension. This finding reinforces the research of Lee \& Rodda (1994), who argue that beliefs and perceptions about disability, and the connection made between disability and an unfamiliar situation, are acquired in children through learning.

One of the main issues raised in the open-ended questionnaires concerns the effect of the type of disability on the ability to accept and the desire for integration among parents and children. This finding indicates the difficulty of meeting people with a background of crime or violence in an authentic, non-prejudiced manner and that people relate such disabilities as a result of choice. Disabilities, in general, are viewed as a permanent condition, and there is a difficulty in believing in rehabilitation and change. Knowledge and familiarity are essential, as they are a present and attentive encounter (Ison, McIntyre, Rothery, Smithers-Sheedy, Goldsmith, Parsonage \& Foy, 2010).

Among the adult population, in particular, the desire has arisen to integrate people with disabilities to create a more diverse society in which different individuals can help each other, get to know each other, learn from experience and learn from each other.

\section{Conclusions}

From the results of the study, it can be concluded that:

- The difficulty in coping with unfamiliar situations significantly affects positive and negative perceptions and behaviours.

- Disabilities, in general, are viewed as a permanent condition, and there is a difficulty in believing in rehabilitation and change. Knowledge and familiarity are essential.

- There is a difficulty in meeting people with a background of crime or violence in an authentic, non-prejudiced manner, and there is a tendency to believe that people relate such disabilities as a result of choice. 
- Getting to know a person with a disability makes it possible to see him from a broader point of view, to adopt his point of view, and act out of awareness of it. This understanding will lead to moral conduct and to action that is consistent with the need of the individual and an understanding of society's ability to benefit from it.

- The relationship of children with disabled peers, which is based on meaningful interactions and broad interaction, contributes to the formation of a positive, humane, and accepting attitude

- Getting to know a person with a disability makes it possible to see him from a broader point of view, to adopt his point of view, and act out of awareness of it. This understanding will lead to moral conduct and to action that is consistent with the need of the individual and an understanding of society's ability to benefit from it.

- School-age children can cope with and examine challenging issues and express independent attitudes and opinions.

- There is a strong effect of parental supervision and responses on the child's actions.

- The individual's family is a central and significant force in transmitting attitudes, behaviours, and hereditary influences that influence his personality and behaviour.

- There is a strong correlation between parent's attitudes to disability and integration and their children's attitude to disability and integration.

Different types of factors affect the suitability of parental attitudes to children's attitudes. In order to pinpoint the factors, further research is needed.

\section{Bibliography}

Adriani F., \& Sonderegger S. (2009), Why Do Parents Socialize Their Children to Behave Prosocially? An Information-Based Theory, Journal of Public Economics, 93(11-12), pp. 11191124.

Algood C.L., Harris C., \& Hong J.S. (2013), Parenting Success and Challenges for Families of Children with Disabilities: An Ecological Systems Analysis, Journal of Human Behavior in the Social Environment, 23(2), pp. 126-136.

Andolina M.W., Jenkins K., Zukin C., \& Keeter S. (2003), Habits from Home, Lessons from School: Influences on Youth Civic Engagement, Political Science and Politics, 36, pp. 275-280.

Bandura A., \& Simon K.M. (1977), The Role of Proximal Intentions in Self-Regulation of Refractory Behavior, Cognitive Therapy and Research, 1(3), pp. 177-193.

Baumrind D. (1977), The Development of Instrumental Competence through Socialization, [in:] A.D. Pick (ed.), Minnesota Symposia on Child Psychology, Minneapolis, MN, pp. 3-46. 
Becker A. (2009), With Whom DID You Play in School Today? The Social World of Very Young Children, Raanana [Hebrew].

Bekkers R. (2007), Intergenerational Transmission of Volunteering, Acta Sociologica, 50(2), pp. 99-114. Ben-David B., \& Nel N. (2013), Applying Bronfenbrenner's Ecological Model to Identify the Negative Influences Facing Children with Physical Disabilities in Rural Areas in Kwa-Zulu Natal, Africa Education Review, 10(3), pp. 410-430.

Berger K.S. (2009), Psicología del Desarrollo: Adultez y Vejez, Madrid.

Berger P.L., \& Luckmann T. (1966), The Social Construction of Reality, New York.

Berk L.E. (2013), Child Development ( $9^{\text {th }}$ edition), New Jersey.

Bowen M. (1966), The Use of Family Theory in Clinical Practice, Comprehensive Psychiatry, 7(5), pp. 345-374.

Bowen M. (1978), Family Therapy in Clinical Practice, New York: Aronson.

Britt S.L. (2016), The Intergenerational Transference of Money Attitudes and Behaviors, The Journal of Consumer Affairs, 50(3), pp. 539-556.

Bronfenbrenner U. (1994), Ecological Models of Human Development, [in:] T. Husen, T.N. Postlethwaite (eds.), International Encyclopedia of Education, 3, pp. 1643-1647.

Brown W.H., Odom S.L., \& McConnell S.R. (eds.) (2008), Social Competence of Young Children: Risk, Disability, and Intervention, Baltimore.

Chubon R.A. (1992), Attitudes Toward Disability: Addressing Fundamentals of Attitude Theory and Research in Rehabilitation Education, Rehabilitation Education, 6, pp. 301-312.

Coatsworth J.D., Duncan L.G., Greenberg M.T., \& Nix R.L. (2010), Changing Parent's Mindfulness, Child Management Skills and Relationship Quality with Their Youth: Results from a Randomized Pilot Intervention Trial, Journal of Child and Family Studies, 19(2), pp. 203-217.

Cohen J., Onunaku N., Clothier S., \& Poppe J. (2005), Helping Young Children Succeed: Strategies to Promote Early Childhood Social and Emotional Development, [in:] Research and Policy Report, National Conference of State Legislatures, Washington, DC.

Corrigan P.W., Markowitz F.E., Watson A., Rowan D., \& Kubiak M.A. (2003), An Attribution Model of Public Discrimination Towards Persons with Mental Illness, Journal of Health and Social Behavior, 44(2), pp. 162-179.

Dahl A., Schuck R.K., \& Campos J.J. (2013), Do Young Toddlers Act On Their Social Preferences?, Developmental Psychology, 49(10), p. 1964-1970.

Damon W., \& Lerner R.M. (eds.) (2006), Handbook of Child Psychology, Theoretical Models of Human Development, Hoboken, New Jersey.

Darling A., \& Steinberg L. (1993), Parenting Style as Context: An Integrative Model, Psychological Bulletin, 113(3), pp. 487-496.

Daruwalla P., \& Darcy S. (2005), Personal and Societal Attitudes to Disability, Annals of Tourism Research, 32(3), pp. 549-570.

DiBiase R., \& Miller P.M. (2012), Predicting Feelings of Cognitive Competence in Head Start Preschoolers, The Journal of Genetic Psychology, 173(1), pp. 23-40.

Dotti Sani G.M., \& Treas J. (2016), Educational Gradients in Parents' Child-Care Time Across Countries, 1965-2012, Journal of Marriage and Family.

Ely R., Gleason J.B., MacGibbon A., \& Zaretsky E. (2001), Attention to Language: Lessons Learned at the Dinner Table, Social Development, 10(3), pp. 355-373.

Endres J.E. (1979), Fear of Death and Attitudinal Dispositions Toward Physical Disability, doctoral dissertation, University of South Carolina, university microfilm, 825, pp. 79-11. 
Erath S.A., \& Bierman K.L. (2006), Aggressive Marital Conflict, Maternal Harsh Punishment, and Child Aggressive-Disruptive Behavior: Evidence for Direct and Mediated Relations, Journal of Family Psychology, 20(2), pp. 217-226.

Esdaile S.A., \& Greenwood K.M. (2003), A Comparison of Mothers' and Fathers' Experience of Parenting Stress and Attributions for Parent-Child Interaction Outcomes, Occupational Therapy International, 10(2), pp. 115-126.

Festinger L. (1957), A Theory of Cognitive Dissonance, vol. 2, Stanford.

Fine J.A. (1978), Castration Anxiety and Self Concept of Physically Normal Children as Related to Perceptual Awareness of Attitudes Toward Physical Deviance, unpublished doctoral dissertation, New York University.

Fonagy P., \& Target M. (2002), Early Intervention and the Development of Self-Regulation, Psychoanalytic Inquiry, 22(3), pp. 307-335.

Gergen K.J. (1986), Correspondence Versus Autonomy in the Language of Understanding Human Action, Metatheory in Social Science, pp. 136-162.

Gergen K., \& Gergen M. (1986), Social Psychology ( $2^{\text {nd }}$ edition), New York.

Geva A. (2014), Consumer Behavior, Raanana: The Open University, Israel [Hebrew].

Gilad D., \& Barak D. (2012), Rehabilitation in an Age of Change in Discourse between People with Disabilities and Society, [in:] M. Hovav, E. Lawental, J. Katan (eds.), Social Work in Israel, Tel Aviv [Hebrew].

Gilmore L., \& Howard G. (2016), Children's Books that Promote Understanding of Difference, Diversity and Disability, Journal of Psychologists and Counsellors in Schools, 26(2), pp. 218-251.

Goffman E. (1963), Stigma: Notes on the Management a Spoiled Identity, New York.

Greenberg J.R., \& Mitchell S.A. (1983), Object Relations in Psychoanalytic Theory, New York.

Halperin E., Elad-Stranger Y., \& Andvolt K. (2016), Attitudes Towards People with Disabilities in 20 Selected Cities in Israel, Hertzelia [Hebrew].

Hammond J., Keeney R., \& Raiffa H. (2006), The Hidden Traps in Decision Making, Harvard Business Review, 84(1), pp. 118-126.

Herrmann E., Call J., Hernández-Lloreda M.V., Hare B., \& Tomasello M. (2007), Humans Have Evolved Specialized Skills of Social Cognition: The Cultural Intelligence Hypothesis, Science, 317(5843), pp. 1360-1366.

Horne M.D. (1985), Attitudes Toward Handicapped Students: Professional, Peer, and Parent Reactions, Hillsdale, New Jersey.

Ison N., McIntyre S., Rothery S., Smithers-Sheedy H., Goldsmith S., Parsonage S., \& Foy L. (2010), 'Just Like You': A Disability Awareness Programme for Children That Enhanced Knowledge, Attitudes and Acceptance: Pilot Study Findings, Developmental Neurorehabilitation, 13(5), pp. 360-368.

Jones N., \& Corrigan P.W. (2014), Understanding Stigma, [in:] P.W. Corrigan (ed.), The Stigma of Disease and Disability: Understanding Causes and Overcoming Injustices, Washington, DC, pp. 9-34.

Kail R.V. (2014), Children and Their Development, Boston.

Krahé B., \& Altwasser C. (2006), Changing Negative Attitudes Towards Persons with Physical Disabilities: An Experimental Intervention, Journal of Community \& Applied Social Psychology, 16(1), pp. 59-69.

Lee R. (2014), Intergenerational Transfers, Social Arrangements, Life Histories, and the Elderly, [in:] M. Weinstein, \& M.A. Lane (eds.), Sociality, Hierarchy, Health: Comparative Biodemography: A Collection of Papers, Washington, DC. 
Lee T., \& Rodda M. (1994), Modification of Attitudes Toward People with Disabilities, Canadian Journal of Rehabilitation, 7(4), pp. 229-238.

Lerner R., Brennan A.L., Noh R.E., \& Wilson C. (2015), The Parenting of Adolescents and Adolescents as Parents: A Developmental Contextual Perspective, Parenthood in America, University of Wisconsin-Madison.

Leviton D. (1975), Education for Death, or Death Becomes Less a Stranger, OMEGA - Journal of Death and Dying, 6(3), pp. 183-191.

Linton S. (1998), Claiming Disability: Knowledge and Identity, New York.

Livneh H. (1980), Disability and Monstrosity: Further Comments, Rehabilitation Literature, 41(1112), pp. $280-283$.

Livneh H. (1982), On the Origins of Negative Attitudes Towards People with Disabilities, Rehabilitation Literature, 43, pp. 338-347.

Livneh H. (1983), Death Anxiety and Attitudes Toward Disabled Persons, Psychological Reports, 53(2), pp. 359-363.

Livneh H. (2012), On the Origins of Negative Attitudes Towards People with Disabilities, The Psychological and Social Impact of Physical Disability, Supra Note, 70.

Matthews T.L., Hempel L.M., \& Howell F.M. (2010), Gender and the Transmission of Civic Engagement: Assessing the Influences on Youth Civic Activity, Sociological Inquiry, 80(3), pp. $448-474$.

Musick M.A., \& Wilson J. (2008), Volunteers: A Social Profile, Bloomington, Indiana.

Nesbit R. (2013), The Influence of Family and Household Members on Individual Volunteer Choices, Nonprofit and Voluntary Sector Quarterly, 42(6), pp. 1134-1154.

O'Brien K.M., Larson C.M., \& Murrell A.R. (2008), Third-Wave Behavior Therapies for Children and Adolescents: Progress, Challenges, and Future Directions, [in:] L.A. Greco, \& S.C. Hayes (eds.), Acceptance \& Mindfulness Treatments for Children \& Adolescents: A Practitioner's Guide, Oakland, CA.

Oliver M. (1995), Understanding Disability: From Theory to Practice, Basingstoke, UK.

Patterson G.R., DeBaryshe B.D., \& Ramsey E. (1989), A Developmental Perspective on Antisocial Behavior, American Psychologist, 44(2), pp. 329-335.

Penner L.A., Dovidio J.F., Piliavin J.A., \& Schroeder D.A. (2005), Prosocial Behavior: Multilevel Perspectives, Annual Review in Psychology, 56, pp. 365-392.

Pleck J.H. (2007), Why Could Father Involvement Benefit Children? Theoretical Perspectives, Applied Developmental Science, 11(4), pp. 196-202.

Rabstejnek C.V. (2012), Family Systems \& Murray Bowen Theory, http://www.houd.info/bowenTheory.pdf, accessed: 01.12.2021.

Reiter S., Kupferberg I., \& Gilat I. (eds.) (2017), Contemporary Issues in the Inclusion of Children and Adults with Special Needs in Israel: A Collection of Papers, Tel Aviv [Hebrew].

Reynolds L.T., \& Herman-Kinney N.J. (2003), Handbook of Symbolic Interactionism, Walnut Creek, CA. Richardson S.A., Goodman N., Hastorf A.H., Dornbusch S.M. (1961), Cultural Uniformity in Reaction to Physical Disabilities, American Sociological Review, 26(2), pp. 241-247.

Robinson C.C. (1996), Psychometric Support for a New Measure of Authoritative, Authoritarian, and Permissive Parenting Practices: Cross-Cultural Connections. Paper Presented in Symposium: New Measures of Parental Child-Rearing Practices Developed in Different Cultural Contexts, XI. Vth Biennial International Society for the Study of Behavioral Development Conference, Quebec City, Canada, August 12-16, 1996. 
Robinson C.C., Mandleco B., Olsen S.F., \& Hart C.H. (1995), Authoritative, Authoritarian, and Permissive Parenting Practices: Development of a New Measure, Psychological Reports, 77, pp. 818-830.

Roessler R., \& Bolton B. (1978), Psychosocial Adjustment to Disability, University Park Press, Baltimore.

Safilios-Rothschild C. (1970), The Sociology and Social Psychology of Disability and Rehabilitation, New York.

Schilder P. (1935), The Image and Appearance of the Human Body, London.

Scrimgeour M.B., Blandon A.Y., Stifter C.A., \& Buss K.A. (2013), Cooperative Coparenting Moderates the Association between Parenting Practices and Children's Prosocial Behavior, Journal of Family Psychology, 27(3), pp. 506-511.

Sigerist F.G. (1964), The Gray Ladies of the American Red Cross, International Review of the Red Cross Archive, 4(36), pp. 121-133.

Siller J. (1964), Reactions to Physical Disability by the Disabled and the Non-disabled, American Psychologist, Research Bulletin, 7, pp. 27-36.

Siller J., Chapman A., Ferguson L., \& Vann D.H. (1967), Studies in Reactions to Disability: XI. Attitudes of the Nondisabled toward the Physically Disabled, New York.

Steadman H.J. (1976), Predicting Dangerousness, [in:] D.J. Madden, J.R. Lion (eds.), Rage. Hate. Assault. And Other Forms of Violence, New York.

Steinberg R., \& Wilhelm M. (2003), Giving: The Next Generation - Parental Effects on Donations (working paper), Brisbane, Australia.

Stern D.N. (1995), The Motherhood Constellation, New York.

Stipek D.J., Gralinski J.H., \& Kopp C.B. (1990), Self-Concept Development in the Toddler Years, Developmental Psychology, 26(6), 972-977.

Tal A. (2013), Stigma Among Employers towards People with Disabilities in General and Psychiatric Disabilities in Particular: Review and Discussion of Existing Legislation, Jerusalem [Hebrew].

Triandis H.C. (1971), Attitude and Attitude Change, Wiley Foundations of Social Psychology Series, New York.

Whiteman M., \& Lukoff I.F. (1965), Attitudes Toward Blindness and Other Physical Handicaps, Journal of Social Psychology, 66, pp. 135-145.

Yamamoto K. (1970), Healthy Students in the College Environment, The Personnel and Guidance Journal, 48(10), pp. 809-816.

Yarom N. (2007), Psychoanalysis in Our Mind - Thoughts on Contemporary Psychoanalytic Practice, Hebrew Psychology publisher [Hebrew].

Ziv N., Moore S., \& Eichengreen A. (2016), Introduction: Disability in Hebrew - An Academic Field in the Making, [in:] S. Moore, N. Ziv, A. Kanter, A. Eichengreen, \& N. Mizrachi (eds.), Disability: A Reader, Jerusalem [Hebrew].

Zukin C., Keeter S., Andolina M., Jenkins K., \& Delli-Carpini M.X. (2006), A New Engagement? Political Participation, Civic Life and the Changing American Citizen, Oxford, UK. 
